\title{
What Matters Most in Online SAP-Enabled Course Learning? A System View of Determinants
}

\author{
Yu Zhao \\ Lamar University \\ yzhao3@lamar.edu
}

\author{
Kakoli Bandyopadhyay \\ Lamar University \\ bandyopaku@lamar.edu
}

\author{
Soumava Bandyopadhyay \\ Lamar University \\ bandyopasu@lamar.edu
}

\begin{abstract}
The purpose of this research is to understand the factors that impact students' perceived learning outcomes, satisfaction, and the intention to continue using the online learning platform in ERP-enabled online courses. The factors considered are online learning platform quality, ERP system quality, information quality, instructor support, and student motivation. We selected SAP as the ERP system that students learn online via any online learning platform, such as Blackboard, for our study. We surveyed business students from four mid-sized state universities in the Unites States. The findings indicate that all factors, except instructor support, are significant determinants of learning outcomes. All factors, except information quality, are significant determinants of student satisfaction. Online learning platform quality and SAP quality are significant determinants of students' intention to continue to take online SAPenabled courses using the current learning platform.
\end{abstract}

\section{Introduction}

Globally, the demand for online education is increasing. The e-learning market worldwide is projected to exceed 243 billion U.S. dollars by 2022 [13, 18]. The number of students taking online courses is also increasing steadily. More faculty worldwide are showing support in favor of online education. The ERP applications market is expected to reach $\$ 84.7$ billion by 2021 , compared with $\$ 82.2$ billion in 2016 [29]. SAP has lead the ERP vendors with the most market share for the last several years. The growth in the number of businesses using ERP applications has an enormous impact on the demand for ERP skills. This is one of the main reasons why many universities have adopted ERP-based curricula in their MIS programs. Since ERP related skills are in great demand, the use of ERP in higher education can improve students' marketability, thus helping them to obtain higher paying jobs. Under such conditions, it is important to understand the factors that contribute to students' learning outcomes, satisfaction, and continued intention to use when they take ERP-based courses online.

The specific purpose of this research is to analyze the determinants of continued use intention of the online learning platform, students' perceived learning outcomes, and satisfaction in ERP-enabled online courses, focusing on a holistic view of the students, instructors, the online platform used to deliver the courses, and the ERP software itself. The online platform used in this study is any course management software, such as Blackboard, used by the universities to deliver online courses. SAP is the selected ERP software used by the students.

In understanding the factors that are likely to impact the online delivery of SAP-based courses to students, we have drawn from several well-known models. These are: 1) The Information Systems (IS) Success Model $[11,12]$; 2) The Social Cognitive Theory, or SCT [3, 4]; 3) The Technology Acceptance Model, or TAM [10]; 4) Context-Specific Theorizing [10]; and 5) Keller's ARCS Model [22]. We begin with a discussion of the research model. Then, in the following sections, we present the research design, the survey, the results, a discussion of the research findings and implications, as well as the limitations of the study and directions for future research.

\section{Research model}

We developed a comprehensive model to understand the effects of the factors that influence the online delivery of SAP-enabled courses. The model is comprised of factors from five different research models and is presented in Figure 1. The model studies the determinants of continued intention to use the online learning platform, student satisfaction, and the students' perceived learning outcomes in SAP-enabled online courses. The research model is explained below in terms of its five distinct but related determinants: 1) Online Learning Platform Quality, 2) SAP quality, 3) 
Information Quality, 4) Perceived Instructor Support, and 5) Student Motivation.

1) Online Learning Platform Quality: Earlier studies $[2,15]$ have concluded that system quality positively influences students' satisfaction and learning outcomes, as well as their intention to use. In our context, we propose that the students will have better learning outcomes, increased satisfaction, and greater willingness to use the online platform if they have positive and constructive interactions with the class through the use of the features of the online learning platform in their online SAP-enabled classes, and if they also find the features of the platform clear, understandable, and easy to use.

2) SAP Quality: DeLone and McLean $[11,12]$ have concluded that system quality, defined as the degree to which the desired characteristics of the information system itself produces the information, positively influences students' satisfaction and learning outcomes, as well as their intention to use the system. In the context of our research, we posit that the students will have better learning outcomes, increased satisfaction, and be more willing to use the online learning platform if an ERP system used in the course is easy to use, userfriendly, stable, secure, fast, and responsive.

3) Information Quality: Prior research [2, 17, 25, 26] has suggested that the information quality defined in terms of accuracy, meaningfulness, and timeliness of the information significantly influences the learning outcomes and satisfaction, and the intention to use by the end-user. We expect that if the information received by students through using the online platform is accurate, relevant, up-to-date, complete, and useful, and if the content of the SAP-enabled online courses designed through the online platform is easy to follow and understand, the students will experience a significantly positive impact on their learning outcomes, satisfaction, and intent to continue to use the platform.

4) Instructor Support: Past research $[14,16]$ has shown that perceived instructor support (defined as the degree to which a student perceives the instructor of a course to be knowledgeable about the course content, to be facilitating the teaching, and providing feedback), has a positive influence on students' learning outcomes. We theorize that students in SAP-enabled online courses that have knowledgeable instructors actively involved in facilitating teaching activities and providing timely feedback will have better learning outcomes, higher satisfaction, and will be more likely to use the learning platform in the future.

5) Student Motivation: Many studies [e.g., 15, 23] have suggested that student motivation, to the extent that it drives the academic performance of a student, will influence the perceived learning outcomes. In our context, it is logical to expect that the students with higher motivation will continue to use the online learning system and perform well in class with more satisfaction and will have better learning outcomes.

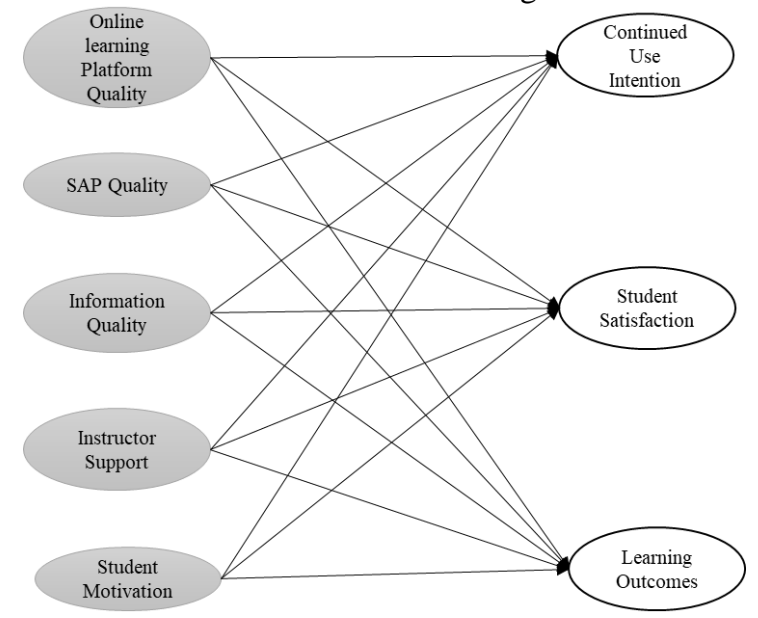

Figure 1. Research model

\section{Research method and data}

Online survey research was used to test our model. We developed a survey instrument based on a comprehensive literature review. We identified appropriate measurements and modified the existing scales in the context of SAP-enabled online course learning. All constructs in the model were operationalized as reflective constructs. They were all assessed on a five-point Likert scale anchored at $1=$ Strongly disagree, and $5=$ Strongly agree .

In this study, we used a purposive sampling method. Our target respondents were representative of the national online student population who have enrolled in at least one SAP-enabled online course. Data were collected at four mid-sized state universities in the United States. All four universities were members of the SAP University Alliance. Initially, we randomly selected 50 students and distributed the survey as a pilot test. The results indicated that there were no ambiguous expressions or confusion. Then, we conducted the main study and received 293 completed responses. Response patterns were examined and checked for "straight lining", which would happen when a respondent marked the same response for a high proportion of the questions. Thirty-two suspicious questionnaires were discarded, which resulted in 261 valid data points that were used for the analysis. Among the valid questionnaires, $46.4 \%$ were completed by males and $53.6 \%$ by females. Undergraduate students made up $71.3 \%$ of the sample, while graduate students made up the remaining 28.7 percent. Of the students who completed the survey, $72.8 \%$ were taking only online classes, and the rest (27.2\%) were taking or had taken both online and face- 
to-face classes. In terms of the number of SAP-enabled courses they were taking, $48.7 \%$ reported they were taking only one course. Other students were taking two $(23.4 \%)$, three $(10.3 \%)$, or four or more $(17.6 \%)$ SAPenabled classes.

\section{Data analysis and results}

Structural equation modeling with partial least squares (PLS-SEM) was used to perform the data analysis. Prior research [e.g., 5, 9, 24] indicates that PLS-SEM is a highly appropriate choice for the estimation method. PLS emphasizes the explanation of endogenous constructs. The constraints regarding the distributional properties (multivariate normality), identification, measurement level, and factor indeterminacy are lower than with covariance-based SEM, and it is a powerful method to analyze complex models using smaller samples [19]. When data sets are large (more than 250), covariance-based structural equation modeling (CB-SEM) and PLS-SEM offer similar results when an appropriate number of indicators are used to measure constructs [20]. The SmartPLS software package was used to evaluate the measurement properties and to test the model. The measurement models and the structural model were estimated.

\subsection{Measurement models}

We first examined the reliability, convergent validity, and discriminant validity of the survey instrument. The indicators' outer loadings were used to evaluate indicator reliability. Table 1 shows that all but two of the loadings are larger than the suggested threshold of 0.708 [6]. According to the rules of thumb for evaluating reflective measurement models, indicators with outer loadings between 0.4 and 0.7 should be considered for removal only if the deletion leads to an increase in composite reliability and the average variance extracted (AVE) is above the suggested threshold value [20]. The two items below the suggested threshold are Motivation4 which has a loading of 0.67 , and Motivation5 which has a loading of 0.6. Table 2 shows that all composite reliabilities are larger than the suggested 0.708 , indicating good internal consistency (reliability); and all AVE values are greater than the suggested .50, indicating good convergent validity of the measurement model [7]. Because all composite reliabilities and AVE are larger than the suggested threshold values, we decided to keep the two items, Motivation4 and Motivation5. For sufficient discriminant validity to be present, items should load higher on the construct it is intended to measure than on any other construct [19], and the square root of each construct's AVE should be higher than its highest correlation with any other construct [28]. Table 1 shows that the items load higher on their own constructs than on any other constructs (cross-loadings). Moreover, Table 3 shows that the square roots of AVE are higher than the correlations among constructs, which provided evidence of discriminant validity. Thus, all criteria used to assess the reliability and validity of construct measures were met.

To assess the common method bias, Harman's single-factor test was conducted. We loaded all variables into an exploratory factor analysis (EFA) and the unrotated factor solution was examined. According to Podsakoff, MacKenzie, Lee, and Podsakoff [27], if a detrimental level of common method bias exists, "(a) a single factor will emerge from exploratory factor analysis (unrotated) or (b) one general factor will account for the majority of the covariance among the measures (p. 889)". In this study, neither occurred. More than one factor emerged to explain the variance, and no single factor accounted for more than half of the covariance among the measures. Therefore, common method bias was not an issue in this study.

To ensure that there is no threat of multicollinearity, we assessed latent variables' variance inflation factor (VIF), which should be lower than 5 [19]. The highest variance inflation factor (VIF) was 3.568, well below the threshold value of 5 , which indicated that there wasn't any collinearity problem. Table 2 lists each construct's VIF value.

\subsection{Structural model}

To evaluate the structural model, coefficients of determination $\left(\mathrm{R}^{2}\right)$, size and significance of path coefficients, and $f^{2}$ effect sizes were measured. Path coefficients and $\mathrm{R}^{2}$ were estimated by running PLS algorithm. The value of $\mathrm{R}^{2}$ is the amount of explained variance of endogenous latent variable. $\mathrm{R}^{2}$ values higher than 0.2 indicate good explanatory power of the endogenous model variables [7]. In our study, students' satisfaction, perceived learning outcomes, and continued SAP use intention are the endogenous latent variables. The model explained 63.9 percent of the variance of learning outcomes $\left(\mathrm{R}^{2}=0.639\right), 68.9$ percent of the variance of student satisfaction $\left(R^{2}=0.689\right)$, and 42.6 percent of the variance of continued use intention $\left(\mathrm{R}^{2}=0.426\right)$. The standardized values of path coefficients are between -1 and +1 , with coefficients close to 0 indicating that the hypothesized relationship is most likely nonsignificant [20]. To determine the statistical significance of the path coefficients, we ran the bootstrapping method using the number of samples as 5,000 and the number of cases as 261, which generated the empirical $\mathrm{t}$ values. The empirical test 
results supported two third of the hypotheses. Information quality had no significant relationship with either student satisfaction or continued use intention but did have a significant positive association with learning outcomes. Instructor support had no significant relationship with either continued use intention or learning outcomes but did have a significant positive association with student satisfaction. Student motivation had no significant relationship with continued use intention. All remaining hypothesized relationships were found to be significant. Specifically, both online learning platform quality and SAP quality had positively significant impact on continued use intention (with path coefficients being $0.4, \mathrm{p}<0.01$ and 0.15 , p $<0.05$, respectively). student satisfaction (with path coefficients of $0.38, \mathrm{p}<0.01$, and $0.26, \mathrm{p}<0.01$, respectively), and learning outcomes (with path coefficients of $0.27, \mathrm{p}<0.01$, and $0.29, \mathrm{p}<0.01$,

Table 1. Loadings and cross loadings

\begin{tabular}{|c|c|c|c|c|c|c|c|c|}
\hline & Information & Instructor & Motivation & $\begin{array}{l}\text { Learning } \\
\text { Outcomes }\end{array}$ & $\begin{array}{c}\text { Continued } \\
\text { Use } \\
\text { Intention }\end{array}$ & Platform & SAP & $\begin{array}{c}\text { Student } \\
\text { Satisfaction }\end{array}$ \\
\hline Information1 & 0.93 & 0.57 & 0.52 & 0.65 & 0.58 & 0.79 & 0.61 & 0.71 \\
\hline Information2 & 0.91 & 0.53 & 0.51 & 0.58 & 0.48 & 0.70 & 0.50 & 0.65 \\
\hline Information3 & 0.93 & 0.58 & 0.56 & 0.61 & 0.59 & 0.77 & 0.57 & 0.68 \\
\hline Information4 & 0.92 & 0.51 & 0.47 & 0.60 & 0.50 & 0.71 & 0.55 & 0.61 \\
\hline Information5 & 0.90 & 0.58 & 0.46 & 0.59 & 0.49 & 0.72 & 0.56 & 0.64 \\
\hline Information6 & 0.88 & 0.59 & 0.47 & 0.62 & 0.51 & 0.72 & 0.52 & 0.64 \\
\hline Information 7 & 0.90 & 0.53 & 0.47 & 0.64 & 0.45 & 0.72 & 0.55 & 0.60 \\
\hline Instructor1 & 0.56 & 0.89 & 0.44 & 0.38 & 0.41 & 0.50 & 0.39 & 0.48 \\
\hline Instructor2 & 0.58 & 0.90 & 0.42 & 0.42 & 0.45 & 0.56 & 0.39 & 0.56 \\
\hline Instructor3 & 0.58 & 0.92 & 0.42 & 0.45 & 0.42 & 0.56 & 0.39 & 0.56 \\
\hline Instructor4 & 0.58 & 0.93 & 0.43 & 0.43 & 0.40 & 0.52 & 0.37 & 0.54 \\
\hline Instructor5 & 0.53 & 0.91 & 0.40 & 0.41 & 0.39 & 0.51 & 0.36 & 0.55 \\
\hline Instructor6 & 0.51 & 0.92 & 0.44 & 0.35 & 0.35 & 0.47 & 0.35 & 0.48 \\
\hline Motivation1 & 0.51 & 0.38 & 0.74 & 0.51 & 0.45 & 0.56 & 0.54 & 0.64 \\
\hline Motivation2 & 0.46 & 0.42 & 0.82 & 0.55 & 0.31 & 0.42 & 0.47 & 0.45 \\
\hline Motivation3 & 0.36 & 0.33 & 0.73 & 0.40 & 0.18 & 0.32 & 0.25 & 0.27 \\
\hline Motivation4 & 0.29 & 0.25 & 0.67 & 0.30 & 0.18 & 0.30 & 0.28 & 0.25 \\
\hline Motivation5 & 0.22 & 0.22 & 0.60 & 0.40 & 0.25 & 0.28 & 0.31 & 0.33 \\
\hline Outcomes1 & 0.57 & 0.38 & 0.55 & 0.90 & 0.35 & 0.59 & 0.55 & 0.57 \\
\hline Outcomes2 & 0.56 & 0.33 & 0.54 & 0.91 & 0.35 & 0.58 & 0.55 & 0.59 \\
\hline Outcomes3 & 0.57 & 0.37 & 0.60 & 0.91 & 0.38 & 0.60 & 0.59 & 0.58 \\
\hline Outcomes4 & 0.64 & 0.42 & 0.57 & 0.91 & 0.47 & 0.67 & 0.67 & 0.67 \\
\hline Outcomes5 & 0.67 & 0.48 & 0.56 & 0.86 & 0.55 & 0.68 & 0.67 & 0.72 \\
\hline PUSE1 & 0.55 & 0.42 & 0.39 & 0.45 & 0.98 & 0.60 & 0.47 & 0.60 \\
\hline PUSE2 & 0.57 & 0.42 & 0.41 & 0.43 & 0.98 & 0.61 & 0.49 & 0.59 \\
\hline PUSE3 & 0.54 & 0.45 & 0.42 & 0.49 & 0.97 & 0.63 & 0.50 & 0.62 \\
\hline Platform1 & 0.70 & 0.52 & 0.47 & 0.59 & 0.56 & 0.85 & 0.49 & 0.68 \\
\hline Platform2 & 0.68 & 0.53 & 0.48 & 0.60 & 0.50 & 0.88 & 0.52 & 0.68 \\
\hline Platform3 & 0.64 & 0.52 & 0.45 & 0.59 & 0.54 & 0.88 & 0.53 & 0.68 \\
\hline Platform4 & 0.67 & 0.53 & 0.46 & 0.64 & 0.51 & 0.86 & 0.56 & 0.69 \\
\hline Platform5 & 0.70 & 0.41 & 0.49 & 0.59 & 0.53 & 0.82 & 0.55 & 0.64 \\
\hline Platform6 & 0.70 & 0.42 & 0.47 & 0.57 & 0.57 & 0.83 & 0.51 & 0.60 \\
\hline Platform7 & 0.76 & 0.49 & 0.50 & 0.61 & 0.55 & 0.86 & 0.50 & 0.60 \\
\hline SAP1 & 0.41 & 0.25 & 0.34 & 0.51 & 0.40 & 0.50 & 0.76 & 0.51 \\
\hline SAP2 & 0.40 & 0.29 & 0.37 & 0.50 & 0.40 & 0.48 & 0.78 & 0.50 \\
\hline SAP3 & 0.53 & 0.32 & 0.47 & 0.59 & 0.42 & 0.51 & 0.88 & 0.61 \\
\hline SAP4 & 0.54 & 0.39 & 0.51 & 0.62 & 0.39 & 0.49 & 0.82 & 0.53 \\
\hline SAP5 & 0.56 & 0.37 & 0.47 & 0.53 & 0.42 & 0.51 & 0.85 & 0.56 \\
\hline SAP6 & 0.59 & 0.41 & 0.58 & 0.63 & 0.46 & 0.57 & 0.90 & 0.65 \\
\hline SATIS1 & 0.65 & 0.51 & 0.59 & 0.67 & 0.58 & 0.71 & 0.62 & 0.94 \\
\hline SATIS2 & 0.72 & 0.61 & 0.56 & 0.66 & 0.56 & 0.73 & 0.64 & 0.95 \\
\hline SATIS3 & 0.64 & 0.52 & 0.53 & 0.64 & 0.59 & 0.71 & 0.64 & 0.93 \\
\hline
\end{tabular}


Table 2. AVE, composite reliability, and VIF

\begin{tabular}{|c|c|c|c|c|}
\hline Construct & AVE & $\begin{array}{c}\text { Composite } \\
\text { Reliability }\end{array}$ & $\begin{array}{c}\text { Number of } \\
\text { Indicators }\end{array}$ & VIF \\
\hline $\begin{array}{c}\text { Continued Use } \\
\text { Intention }\end{array}$ & 0.95 & 0.98 & 3 & 1.82 \\
\hline Information Quality & 0.83 & 0.97 & 7 & 3.57 \\
\hline Instructor Support & 0.83 & 0.97 & 6 & 1.78 \\
\hline Learning Outcomes & 0.80 & 0.95 & 5 & 2.87 \\
\hline Student Motivation & 0.51 & 0.84 & 5 & 1.89 \\
\hline $\begin{array}{c}\text { Online learning } \\
\text { Platform Quality }\end{array}$ & 0.73 & 0.95 & 7 & 4.02 \\
\hline SAP Quality & 0.69 & 0.93 & 6 & 2.27 \\
\hline Student Satisfaction & 0.88 & 0.96 & 3 & 3.43 \\
\hline
\end{tabular}

Table 3. Correlations among latent variables

\begin{tabular}{|l|l|l|l|l|l|l|l|l|}
\hline Construct & 1 & 2 & 3 & 4 & 5 & 6 & 7 & 8 \\
\hline $\begin{array}{l}\text { 1. Continued } \\
\text { Use } \\
\text { Intention }\end{array}$ & $\mathbf{0 . 9 7}$ & & & & & & & \\
\hline $\begin{array}{l}\text { 2. } \\
\text { Information }\end{array}$ & 0.57 & $\mathbf{0 . 9 1}$ & & & & & & \\
\hline 3. Instructor & 0.44 & 0.61 & $\mathbf{0 . 9 1}$ & & & & & \\
\hline $\begin{array}{l}\text { 4. Learning } \\
\text { Outcomes }\end{array}$ & 0.47 & 0.67 & 0.45 & $\mathbf{0 . 9 0}$ & & & & \\
\hline $\begin{array}{l}\text { 5. } \\
\text { Motivation }\end{array}$ & 0.42 & 0.54 & 0.47 & 0.63 & $\mathbf{0 . 7 2}$ & & & \\
\hline 6. Platform & 0.63 & 0.81 & 0.57 & 0.70 & 0.55 & $\mathbf{0 . 8 6}$ & & \\
\hline 7. SAP & 0.50 & 0.61 & 0.41 & 0.68 & 0.55 & 0.61 & $\mathbf{0 . 8 3}$ & \\
\hline $\begin{array}{l}\text { 8. Student } \\
\text { Satisfaction }\end{array}$ & 0.61 & 0.71 & 0.58 & 0.70 & 0.59 & 0.76 & 0.68 & $\mathbf{0 . 9 4}$ \\
\hline
\end{tabular}

Table 4. Structural parameter estimates

\begin{tabular}{|c|c|c|c|}
\hline & Path coefficients & T Statistics & Effect size \\
\hline Information quality-> Learning Outcomes & 0.17 & $2.18 * *$ & 0.02 \\
\hline Information quality -> Continued Use Intention & 0.08 & 0.82 (n. s.) & 0.00 \\
\hline Information quality-> Student satisfaction & 0.10 & 1.25 (n. s.) & 0.01 \\
\hline Instructor support -> Learning Outcomes & -0.05 & 0.96 (n. s.) & 0.00 \\
\hline Instructor support -> Continued Use Intention & 0.09 & 1.05 (n. s.) & 0.01 \\
\hline Instructor support -> Student satisfaction & 0.15 & $2.56 * *$ & 0.04 \\
\hline Student motivation -> Learning Outcomes & 0.25 & $4.14 * * *$ & 0.10 \\
\hline Student motivation -> Continued Use Intention & 0.02 & 0.29 (n. s.) & 0.00 \\
\hline Student motivation -> Student satisfaction & 0.12 & $1.88 *$ & 0.03 \\
\hline Online platform quality-> Learning Outcomes & 0.27 & $3.44 * * *$ & 0.06 \\
\hline Online platform quality -> Continued Use Intention & 0.40 & $4.32 * * *$ & 0.09 \\
\hline Online platform quality -> Student satisfaction & 0.38 & $4.87 * * *$ & 0.14 \\
\hline SAP quality -> Learning Outcomes & 0.29 & $4.77 * * *$ & 0.13 \\
\hline SAP quality-> Continued Use Intention & 0.15 & $2.20 * *$ & 0.02 \\
\hline SAP quality -> Student satisfaction & 0.26 & $4.02 * * * 11$ & 0.11 \\
\hline n. s.: nonsignificant; $* p<0.1 ; * p<0.05 ; * * p<0.01$ & & 0 \\
\hline
\end{tabular}




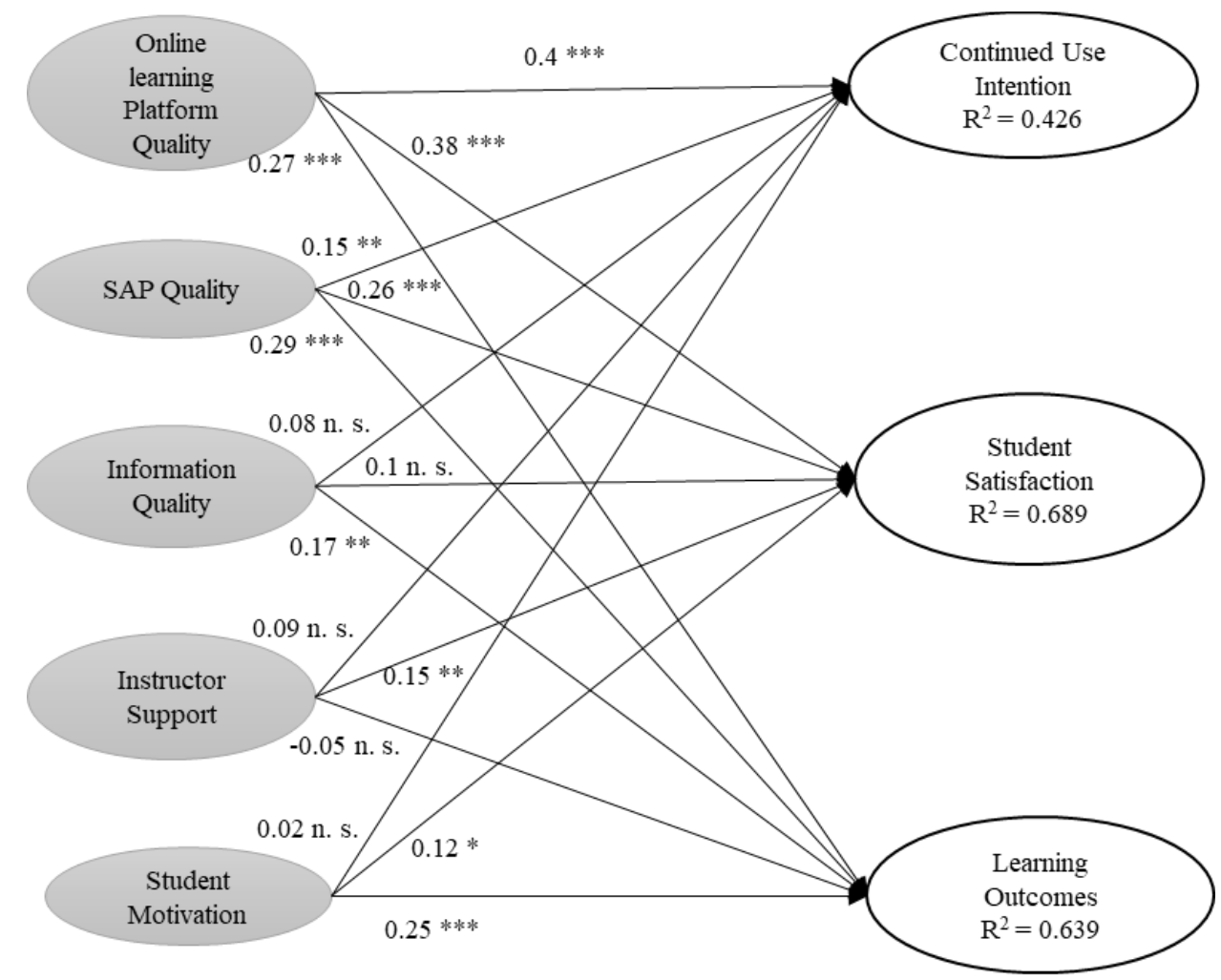

n. s.: nonsignificant; ${ }^{*} \mathrm{p}<0.1 ;{ }^{*} \mathrm{k}<<0.05 ;{ }^{*} k^{*} \mathrm{p}<0.01$

Figure 2. Estimated relationships in the structural model

respectively). Student motivation had a positively significant relationship with student satisfaction (with path coefficient of $0.12, p<0.1$ ) and learning outcomes (with path coefficient of $0.25, \mathrm{p}<0.01$ ). Table 4 exhibits parameters estimated in the structural model. Figure 2 shows the estimated relationships in the structural model.

The effect size $f^{2}$ specifies the relevance of constructs in explaining selected endogenous latent constructs, where values of $0.02,0.15$, and 0.35 represent small, medium, and large effects, respectively of the exogenous latent variable [8]. Effect size $\left(f^{2}\right)$ is calculated by the formula ( $R^{2}$ included $-R^{2}$ excluded $) /(1$ $-R^{2}$ included), where $R^{2}$ included and $R^{2}$ excluded are the $R^{2}$ values of the endogenous latent variable when one chosen exogenous latent variable is included or excluded from the model [20]. Table 4 lists the effect size for every relationship in the model.

The results demonstrated that online learning platform quality and SAP quality were strong determinants of student continued use intention (to take online SAP-enabled courses), while online learning platform quality was more significantly related to continued use intention than SAP quality. Except information quality, all exogenous constructs were significantly related to student satisfaction. Among these determinants, online learning platform quality had the most significant impact on student satisfaction, followed by SAP quality. Except instructor support, all exogenous constructs had a significant impact on learning outcomes. While SAP quality was the most significant determinant, student motivation had the second most significant impact on learning outcomes.

\section{Discussion and implications}

Based on five theories and previous empirical studies, this article presents an integrated view of online learning success. The primary objective of this study was to find the most significant factors that impact students' online SAP enabled course learning outcomes, satisfaction, and intention to use online learning platform to take SAP-enabled course in the future. Students' satisfaction and learning outcomes were determined $\left(R^{2}\right.$ satisfaction $=0.689$ and $R^{2}$ outcomes $=$ $0.639)$ better than continued platform usage $\left(R^{2}=\right.$ $0.426)$. Only the quality of the learning platform and SAP system quality were significant determinants of 
continued platform usage. One possible explanation is that quality of systems are relatively stable compared to information quality and instructor support, which depend on the instructor. Also, the current instructor may not teach other SAP-enabled online courses that students might be offered. Thus, students' perception on the current course's information quality and instructor support cannot significantly affect their intention to use the online learning platform to take other SAP-enabled courses. The same logic applies to student motivation, which might vary from course to course.

The quality of the learning platform and that of the SAP system were the most significant determinants of students' satisfaction and learning outcomes. While previous research about online learning success either only considered the characteristics of an online learning system [e.g., 1], or only considered the ERP system itself [e.g., 2], we examined the impact of both systems. In this context, distance learners were dealing with two kinds of systems: an online learning platform used to learn SAP systems, and the complex SAP system itself.

Based on an extensive literature review, we contextualized the quality of online learning platform into ease of use and interactivity. In consistence with previous research which emphasized ease of use and interactivity as important determinants of perceived satisfaction and learning outcomes [1, 14], this study further found that the quality of the online learning platform had the most significant impact on continued use intention and satisfaction. This highlighted the importance of online learning platform to be perceived as user friendly and interactivity. Features such as discussion boards, course Emails, instant messaging, and virtual conference might help interactions. For information systems (IS) practitioners, online learning platform design should focus on improvement of user friendliness and interactivity. For IS researchers, more studies on design science are needed to further investigate the features of online learning platforms. For IS educators, online course interface design should be straightforward, menu items should be easy to find, and more interactivity features should be enabled.

Our results indicated that SAP system quality was the most significant determinant of learning outcomes. While previous research didn't pay much attention to the impact of complex software on learning outcomes, our study filled that gap by investigating the effects of SAP system quality. While SAP systems are complex in nature, the detailed oriented instructions and step-bystep video demonstrations might help students to perceive SAP systems as ease of use. IS practitioners are encouraged to maintain the stability, accessibility, and availability of SAP systems, as well as to improve their ease of use.
Our study indicated that information quality had a significant impact on learning outcomes only. Since online learning is a self-paced activity, the quality of information necessary for students is high. Although we could not establish a positive link between information quality and student satisfaction, we found perceived instructor support had a positively significant relationship with student satisfaction. As content providers, instructors provide instructions that guide distance learners to study and stimulate their interests. Their support enhances students' positive learning experiences which is referred to as satisfaction. Thus, IS educators need to provide high quality information, motivate students by setting appropriate course objectives, and provide positive feedback concerning student progress and constructive suggestions to improve.

While the importance of student motivation has been recognized by researchers, prior research results are inconsistent about the relationship among students' selfmotivation, learning outcomes and satisfaction. Our study found a positively significant relationship between student motivation and learning outcomes, and between student motivation and satisfaction. For IS researchers, a deeper investigation of how to effectively motivate distance learners is recommended. IS educators are encouraged to stimulate students' interests on ERP systems and to help them understand the benefits.

Although this study was based on an online learning environment in universities, these findings can be applied to industry as well. Companies using virtual training to help employees and clients learn technology may benefit from this study.

\section{Limitations and future research}

Our study has a few limitations. First, self-reporting scales were used to measure all the variables, which raised the concern of common method bias. Although Harman's single factor test was conducted to rule out this concern, it is better to use objective data from various resources. Second, we collected sample data from four mid-sized state universities in the United States. Since distance learning has been an increasing trend around the world and complex software such as SAP has been applied widely, future research may test the model across different cultural settings. Third, we didn't have the chance to explore the dynamic mechanism among determinants of success factors of online learning. In the future, further investigation is encouraged to conduct a longitudinal research. Study variables should be collected at multiple stages to examine their dynamic relationships. Finally, although 
we strive to develop a comprehensive and integrative research model, it's impossible to include all possible factors. Future research may examine the moderating and mediating effects of other variables not included in our study.

\section{Conclusion}

Based on established theories and empirical research, we examined the strength and importance of a set of essential determinants of student success in online SAP-enabled courses. The findings of the study highlighted the importance of quality of online learning platforms and SAP systems as the most significant determinants of students' continued intention to take SAP-enabled courses, satisfaction, and perceived learning outcomes. Additionally, we found information quality to have a positively significant influence on learning outcomes, and perceived instructor support to have a positively significant influence on student satisfaction. Moreover, the results showed that students' self-motivation played a crucial role in ensuring learning outcomes and satisfaction. With the increasing demand of online education and the challenging nature of training of complex software like SAP, this study has made a significant contribution to understanding the determinants of success factors in online learning better. Implications for IS educators, researchers, and practitioners have been discussed. Future research is encouraged to further investigate the online learning of complex software.

\section{References}

[1] K. A. Alshare, R. D. Freeze, P. L. Lane, and H. J. Wen, "The impacts of system and human factors on online learning systems use and learner satisfaction", Decision Sciences Journal of Innovative Education, 2011, 9(3), pp. 437-461.

[2] K. A. Alshare, and P. L. Lane, "Predicting studentperceived learning outcomes and satisfaction in ERP courses: An empirical investigation", Communications of the Association for Information Systems, 2011, 28, pp. 571-584.

[3] A. Bandura, "Self-efficacy mechanism in human agency”, American Psychologist, 1982, 37, pp. 122-147.

[4] A. Bandura, "The explanatory and predictive scope of self-efficacy theory", Journal of Social and Clinical Psychology, 1986, 4(3), pp. 359-373.

[5] L. Chen, A. Keys, and D. Gaber, "How does ERPSim influence students' perceived learning outcomes in an information systems course? An empirical study", Journal of Information Systems Education, 2015, 26(2), pp. 135-146.
[6] W. W. Chin, The partial least squares approach for structural equation modeling. In G. A. Marcoulides (Ed.), Methodology for business and management. Modern methods for business research (pp. 295-336). Mahwah, NJ, US: Lawrence Erlbaum Associates Publishers, 1998.

[7] W. W. Chin, How to write up and report PLS analyses. In V. Esposito Vinzi, W. W. Chin, J. Henseler, \& H. Wang (Eds.), Handbook of partial least squares (pp. 655-690). Berlin: Springer, 2010.

[8] J. Cohen, Statistical power analysis for the behavioral sciences (2nd ed.). Hillsdale, NJ: Lawrence Erlbaum, 1988.

[9] Y. M. Dang, Y. G. Zhang, S. Ravindran, and T. Osmonbekov, "Examining student satisfaction and gender differences in technology-supported, blended learning", Journal of Information Systems Education, 2016, 27(2), pp. 119-130.

[10] F.D. Davis, "Perceived usefulness, perceived ease of use, and user acceptance of information technology", MIS Quarterly, 1989, 13(3), pp. 319-339.

[11] W.H. DeLone, and E.R. McLean, "Information systems success: The quest for the dependent variable", Information Systems Research, 1992, 3(1), pp. 60-95.

[12] W. H. DeLone, and E. R. McLean, "The DeLone and McLean model of information systems success: A ten-year update", Journal of Management Information Systems, 2003, 19(4), pp. 9-30.

[13] E-learning and digital education - Statistics \& Facts, https://www.statista.com/topics/3115/e-learning-and-digitaleducation/

[14] S. Eom, and N. Ashill, "The determinants of students' perceived learning outcomes and satisfaction in university online education: An update", Decision Sciences Journal of Innovative Education, 2016, 14(2), pp. 185-215.

[15] S. Eom, and N. Ashill, "A system's view of e-learning success model", Decision Sciences Journal of Innovative Education, 2018, 16(1), pp. 42-76.

[16] S. B. Eom, H. J. Wen, and N. Ashill, "The determinants of students' perceived learning outcomes and satisfaction in university online education: An empirical investigation", Decision Sciences Journal of Innovative Education, 2006, 4(2), pp. 215-235.

[17] R. D. Freeze, K. A. Alshare, P. L. Lane, and H. J. Wen, 'IS success model in e-learning context based on students' perceptions", Journal of Information Systems Education, 2010, 21(2), pp. 173-184.

[18] Global E-Learning Market 2017 to Boom \$275.10 Billion Value by 2022 at a CAGR of $7.5 \%$ - Orbis Research https://www.reuters.com/brandfeatures/venturecapital/article?id=11353 
[19] J. F. Hair, C. M. Ringle, and M. Sarstedt, "PLS-SEM: Indeed a silver bullet", Journal of Marketing Theory and Practice, 2011, 19(2), pp. 139-152.

[20] J. F. Hair, G. T. M. Hult, C. Ringle, and M. Sarstedt, $A$ primer on partial least squares structural equation modeling (PLS-SEM). Thousand Oaks, CA: Sage Publications, 2014.

[21] W. Hong, F. K. Chan, J. Y. Thong, L. C. Chasalow, and G. Dhillon, "A framework and guidelines for context-specific theorizing in information systems research", Information Systems Research, 2014, 25(1), pp. 111-136.

[22] J. Keller, "Development and use of the ARCS model of motivational design", Journal of Instructional Development, 1987, 10(3), pp. 2-10.

[23] J. M. Keller, Motivational design for learning and performance: The ARCS model approach. Springer Science \& Business Media, 2009.

[24] C. Liang, D. Gu, F. Tao, H. K. Jain, Y. Zhao, and B. Ding, "Influence of mechanism of patient-accessible hospital information system implementation on doctor-patient relationships: A service fairness perspective", Information \& Management, 2017, 54(1), pp. 57-72.

[25] H. F. Lin, "Measuring online learning systems success: Applying the updated Delone and Mclean model", Cyber Psychology \& Behavior, 2007, 10(6), pp. 817-820.

[26] H. Mohammadi, "Investigating users' perspectives on elearning: An integration of TAM and IS success model", Computers in Human Behavior, 2015, 45, pp. 359-374.

[27] P. M. Podsakoff, S. B. MacKenzie, J. Y. Lee, and N. P. Podsakoff, "Common method biases in behavioral research: A critical review of the literature and recommended remedies", Journal of Applied Psychology, 2003, 88(5), pp. 879-903.

[28] D. Straub, M. C. Boudreau, and D. Gefen, "Validation guidelines for IS positivist research", Communications of the Association for Information Systems, 2004, 13, pp. 380-427.

[29] Top 10 ERP Software Vendors and Market Forecast 2016-2021, https://www.appsruntheworld.com/top-10-erpsoftware-vendors-and-market-forecast/ 